Article

\title{
Fence Shaping of Substrate Integrated Fan-Beam Electric Dipole for High-Band 5G
}

\author{
Waleed El-Halwagy ${ }^{1, * \mathbb{D}}$, Rashid Mirzavand ${ }^{1} \mathbb{D}$, Jordan Melzer $^{2}$, Masum Hossain ${ }^{1}$ and \\ Pedram Mousavi ${ }^{1}$ (D) \\ 1 Electrical and Computer Engineering Department, University of Alberta, Edmonton T6G 1H9, Canada; \\ mirzavan@ualberta.ca (R.M.), masum@ualberta.ca (M.H.), pmousavi@ualberta.ca (P.M.) \\ 2 TELUS Communications, Ottawa, Ontario K1P 0A6, Canada; jordan.melzer@telus.com \\ * Correspondence: elhalwag@ualberta.ca
}

Received: 17 April 2019; Accepted: 13 May 2019; Published: 15 May 2019

check for updates

\begin{abstract}
This work presents fence shaping for dipole antenna operating at 5G high-band frequencies. A via fence is employed around the dipole to suppress back radiation. By varying the geometric shape of the fence, the dipole's radiation characteristics can be controlled, which adds an additional degree of freedom to the design. This was investigated by studying different fence shapes, namely rectangular-, U-, and V-shaped fences. The wide bandwidth (higher than $6.5 \mathrm{GHz}$ ) centered around $28 \mathrm{GHz}$, and the stable radiation performance from $24 \mathrm{GHz}$ to $32 \mathrm{GHz}$ made the proposed structure capable of supporting multiple $5 \mathrm{G}$ frequency bands and the fence shaping help modulate the gain and HPBW of the dipole. All fabricated prototypes attained front-to-back radiation ratio $(\mathrm{F} / \mathrm{B})$ higher than $36 \mathrm{~dB}$, with good gain/HPBW performances of $14.1 \mathrm{dBi} / 103.7^{\circ}, 13.5 \mathrm{dBi} / 118^{\circ}$, and $12.6 \mathrm{dBi} / 133^{\circ}$ from the $\mathrm{V}$-fence, $\mathrm{U}$-fence, and rectangular fence $4 \times 1$ arrays, respectively.
\end{abstract}

Keywords: 5G; fence shaping; array; dipole; fan-beam; edge; via

\section{Introduction}

In wireless communication transceivers, high performance integrated antenna design is very critical for achieving a good signal-to-noise ratio performance [1]. Recently, antenna design for high-band 5G wireless has greatly attracted the attention of the research community in both industry and academia, owing to the promises of $5 \mathrm{G}$ to overcome the limited bandwidth and data rates of the 4G standard, together with the ability to support the expected mobile traffic explosion by 2020 [2-5].

Designing mmWave antennas is challenging, especially on the mobile device side, which is the target of this work. The free space path loss that accompanies mmWave communications is much higher than that with the current sub-6 GHz mobile standards, owing to the high frequency propagation [6]. This dictates the need for directional high gain antennas. In addition, for better coverage, a wide fan beam is required [7]. Moreover, the antenna needs to be implemented at the mobile device edge [8]. For area-limited mobile devices, implementing the array at the device's edge can result in an area-efficient full 3D space coverage, as opposed to planar structures $[9,10]$ offering only sub-hemispherical coverage [11]. To summarize, for the mobile device mmWave edge antenna to be able to achieve good performance, it requires a gain higher than $10 \mathrm{dBi}$, a fan beam with $\mathrm{HPBW}$ in the elevation plane $\left(\mathrm{HPBW}_{\mathrm{El}}\right)$ greater than $100^{\circ}$ [8], together with compact size and high front-to-back radiation ratio $(\mathrm{F} / \mathrm{B})$ to avoid interaction with the RF transceiver circuits. Achieving all those requirements at the same time is challenging. The focus of this work was to develop and design an antenna that is capable of meeting all of those specifications simultaneously.

A couple of interesting edge-implemented antenna designs exist in the literature [12-15]. However, they suffer from some limitations. In Reference [12,13], a $28 \mathrm{GHz}$ mesh grid array was presented. 
They employed a large number of array elements, which requires a large number of phase shifters for beamsteering, which in turn complicates the design of the phase shifter RF chip and results in higher power consumption. In Reference [14], a Ka-band dipole array loaded horn antenna was introduced, which suffered low F/B and HPBW. A beamsteering phased array, implemented as 16 cavity-backed slot antennas, proposed in Reference [15] to operate in the $28 \mathrm{GHz}$ band, suffered from degraded low $\mathrm{F} / \mathrm{B}$ and HPBW. Hence, it can be concluded that the aforementioned structures are not able to achieve the high gain, $\mathrm{HPBW}$, and $\mathrm{F} / \mathrm{B}$ requirements simultaneously.

In Reference [16], the authors proposed a mm-Wave electric dipole surrounded by a rectangular fence to suppress back radiation that simultaneously achieved high gain, $\mathrm{F} / \mathrm{B}$, and HPBW in the elevation plane $\left(\mathrm{HPBW}_{\mathrm{El}}\right)$. In fact, the fence did more than just suppressing the back radiation. Modulating the geometric shape of the fence helped control and improve the dipole's radiation performance. This is a property of the electric dipole which magneto-electric dipoles $[17,18]$ cannot offer. Fence shaping adds more degrees of freedom, and gives more flexibility to the electric dipole design to satisfy different scenarios. In this work, the fence shaping capability of the electric dipole was studied and analyzed where different fence shapes (shown in Figure 1) were examined, namely, $\mathrm{V}$-shaped and U-shaped fences, in addition to the conventional rectangular fence. The proposed structure features stable radiation pattern over a wide frequency range from $24 \mathrm{GHz}$ to $32 \mathrm{GHz}$ allowing it to support multiple 5G bands, more specifically, the $24 \mathrm{GHz}$, the $26 \mathrm{GHz}$, the $28 \mathrm{GHz}$ and the $32 \mathrm{GHz}$ frequency bands $[19,20]$.

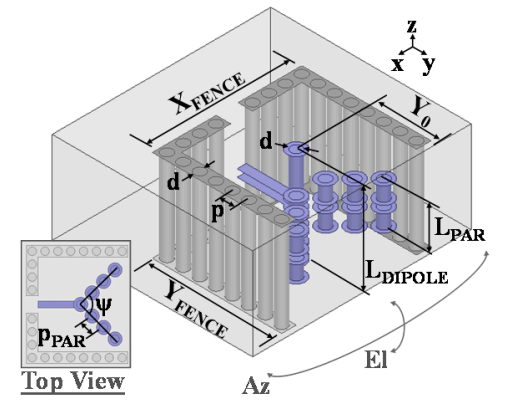

(a)

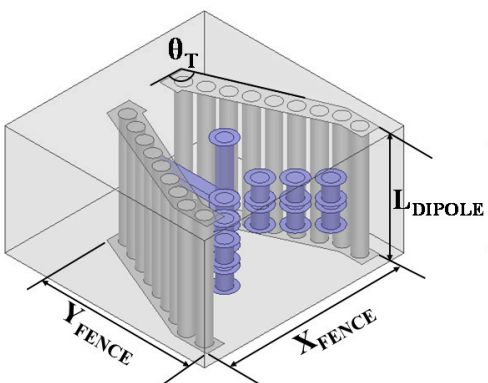

(b)

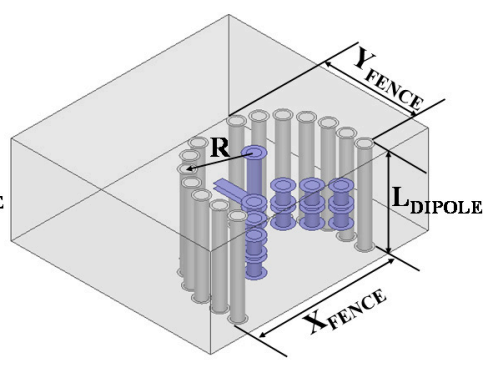

(c)

Figure 1. Electric dipole with different fence shapes implemented at the edge of Rogers RO5880 substrate. (a) Rectangular fence. (b) V-shaped fence. (c) U-shaped fence.

The rest of the paper is organized as follows; the conventional dipole antenna with rectangular fence is summarized in Section 2.1. The effect of fence shaping is introduced in Section 2.2, and the performance comparison between the different fences is presented in Section 2.3. Finally, the fabricated prototypes, measurement results, and comparison with the state-of-the-art structures are presented in Section 3.

\section{Materials and Methods}

\subsection{Dipole with Conventional Rectangular Fence}

The geometry of the dipole with an $X_{F E N C E} \times Y_{F E N C E}$ rectangular fence is shown in Figure 1a. For higher dipole gain, parasitic vias were employed ahead of the dipole. They were flared with angle $\psi$ for $\mathrm{HPBW}_{\mathrm{El}}$ improvement. A detailed parametric study on the dipole was introduced in Reference [15]. To set a reference for this study, a summary of the optimized dipole parameters is provided in Table 1, achieving $7.2 \mathrm{dBi}$ gain, $36.6 \mathrm{~dB} \mathrm{~F} / \mathrm{B}$, and $135.1^{\circ} \mathrm{HPBW}_{\mathrm{El}}$. Throughout this paper, the dipole parameters will be set as in Table 1 for optimal performance. The fence dimensions and shape had a great influence on the radiation performance of the antenna [21,22]. For example, higher gain was achieved by modulating the rectangular fence dimensions from $X_{F E N C E} \times Y_{F E N C E}=\lambda_{d} \times \lambda_{d}$ to $1.2 \lambda_{d} \times \lambda_{d}$, resulting in the gain increasing from 7.2 to $8.7 \mathrm{dBi}$. However, this came at the cost of 
severe degradation in the $\mathrm{HPBW}_{\mathrm{El}}$ and $\mathrm{F} / \mathrm{B}$ by $44.6^{\circ}$ and $12.1 \mathrm{~dB}$, respectively, as illustrated in Figure 2 . Hence, simply changing the fence dimensions is sub-optimal. A better way to provide the required gain enhancement without sacrificing the $\mathrm{HPBW}_{\mathrm{El}}$ and $\mathrm{F} / \mathrm{B}$ is fence shaping [23].

Table 1. Electric dipole design parameters.

\begin{tabular}{ccccccccc}
\hline $\mathbf{L}_{\text {DIPOLE }}$ & $\mathbf{Y}_{\mathbf{0}}$ & $\mathbf{d}$ & $\mathbf{p}$ & $\mathbf{X}_{\text {FENCE }}$ & $\mathbf{Y}_{\text {FENCE }}$ & LPAR $_{\text {PAR }}$ & $\psi$ & p PAR \\
\hline $0.7 \lambda_{\mathrm{d}}$ & $0.54 \lambda_{\mathrm{d}}$ & $0.6 \mathrm{~mm}$ & $0.83 \mathrm{~mm}$ & $\lambda_{\mathrm{d}}{ }^{*}$ & $\lambda_{\mathrm{d}}$ & $0.26 \lambda_{\mathrm{d}}$ & $80^{\circ}$ & $0.8 \mathrm{~mm}$ \\
\hline \multicolumn{8}{c}{${ }^{*} \lambda_{\mathrm{d}}$ : The wavelength inside the RO5880 Slab at $28 \mathrm{GHz}}$.
\end{tabular}
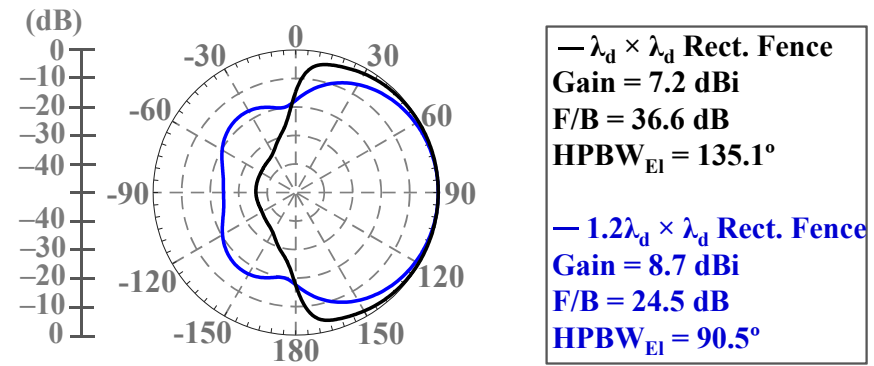

Figure 2. The radiation pattern of the rectangular fenced dipole with $X_{F E N C E} \times Y_{F E N C E}=\lambda_{d} \times \lambda_{d}$ and $1.2 \lambda_{d} \times \lambda_{d}$.

\subsection{Dipole Shaped Fence}

In this section, the fence shaping capability of the proposed electric dipole is introduced. The concept of fence shaping is presented with the aid of parametric study and electric field distribution on two case studies, namely the V-shaped and U-shaped fences, and compares their performance with the conventional rectangular fence case.

The geometry of the dipole with the fence tapered in a V-shaped fashion is shown in Figure 1b. The V-fence is defined by its size span $X_{F E N C E} \times Y_{F E N C E}$ and the tapering angle $\left(\theta_{T}\right)$. The V-fence size $X_{F E N C E} \times Y_{F E N C E}$ is set to $\lambda_{d} \times \lambda_{d}$, like the rectangular fence, for optimal performance. To get more insight into the design perspectives of the tapered V-fence, a parametric study was conducted on $\theta_{T}$. Figure 3 shows the simulated gain, $\mathrm{HPBW}_{\mathrm{El}}$, and $\mathrm{F} / \mathrm{B}$ plotted versus $\theta_{T}$ at $28 \mathrm{GHz}$. As $\theta_{T}$ increased beyond $90^{\circ}$ - where $\theta_{T}=90^{\circ}$ corresponds to the rectangular fence case-the gain increases. This was accompanied by a decrease in the HPBW $\mathrm{El}_{\mathrm{El}}$. However, the decrease in the $\mathrm{HPBW}_{\mathrm{El}}$ as $\theta_{T}$ increased was not steep where the $\mathrm{HPBW}_{\mathrm{El}}$ was still wide and greater than $100^{\circ}$, up to $\theta_{T}=125^{\circ}$. For the different tapering angles of the $\mathrm{V}$-fence, the antenna exhibited good $\mathrm{F} / \mathrm{B}$ higher than $30 \mathrm{~dB}$. The implemented dipole with V-fence prototype was designed with $\theta_{T}=115^{\circ}$ for optimal $\mathrm{F} / \mathrm{B}$, providing $37.6 \mathrm{~dB} F / \mathrm{B}$, 108.2 ${ }^{\circ} \mathrm{HPBW}_{\mathrm{El}}$, and $8.9 \mathrm{dBi}$ gain.

Compared to the $1.2 \lambda_{d} \times \lambda_{d}$ rectangular fence dipole, the $115^{\circ}$ tapered $\mathrm{V}$-fence dipole achieved $0.2 \mathrm{dBi}$ higher gain, $13.1 \mathrm{~dB}$ higher $\mathrm{F} / \mathrm{B}$, and $17.7^{\circ}$ higher $\mathrm{HPBW}_{\mathrm{El}}$. This shows the effectiveness of shaping the dipole's fence in achieving improved radiation performance, compared to just resizing the rectangular fence. Thus, when higher dipole gain is required, employing a $115^{\circ}$ tapered V-fence is a better option than resizing the rectangular fence from $\lambda_{d} \times \lambda_{d}$ to $1.2 \lambda_{d} \times \lambda_{d}$. This can also be explained using the electric field distributions shown in Figure 4, where both the $115^{\circ}$ tapered V-fence and the $1.2 \lambda_{d} \times \lambda_{d}$ rectangular fence dipoles had higher peak field intensity at the front face compared to the $\lambda_{d} \times \lambda_{d}$ rectangular fence dipole, indicating higher gain. However, the $115^{\circ}$ tapered $V$-fence dipole had lower field intensity at the back dipole face and more uniform field intensity along the z-axis of the front dipole face compared to the $1.2 \lambda_{d} \times \lambda_{d}$ rectangular fence dipoles, indicating lower back radiation (enhanced F/B) and higher $\mathrm{HPBW}_{\mathrm{El}}$, respectively. 


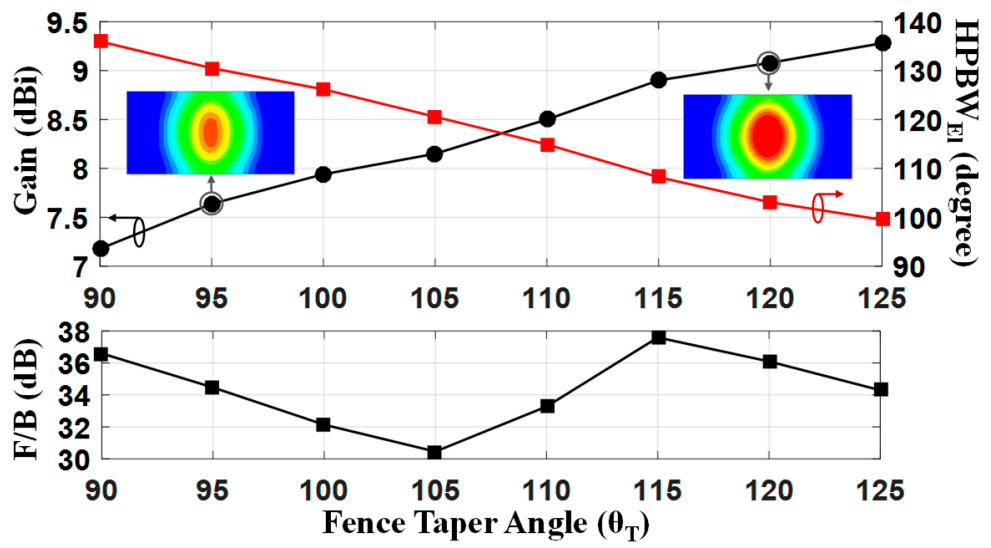

Figure 3. The simulated gain, $\mathrm{HPBW}_{\mathrm{El}}$, and $\mathrm{F} / \mathrm{B}$ versus the $\mathrm{V}$-fence taper angle at $28 \mathrm{GHz}$, and the electric field at the dipole front face at $\theta_{\mathrm{T}}=95^{\circ}$ and $120^{\circ}$.
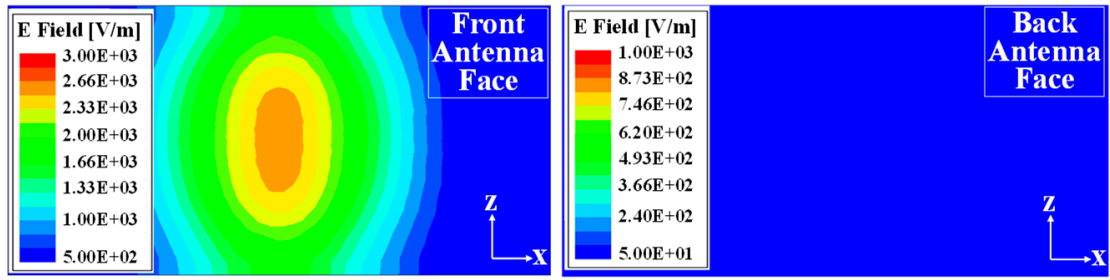

(a)
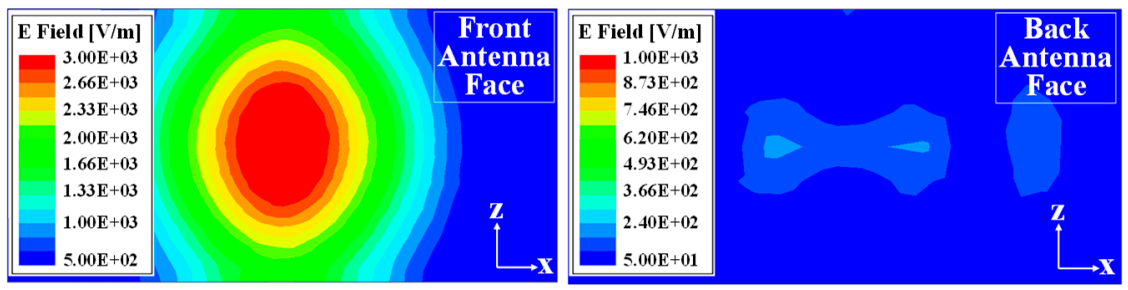

(b)
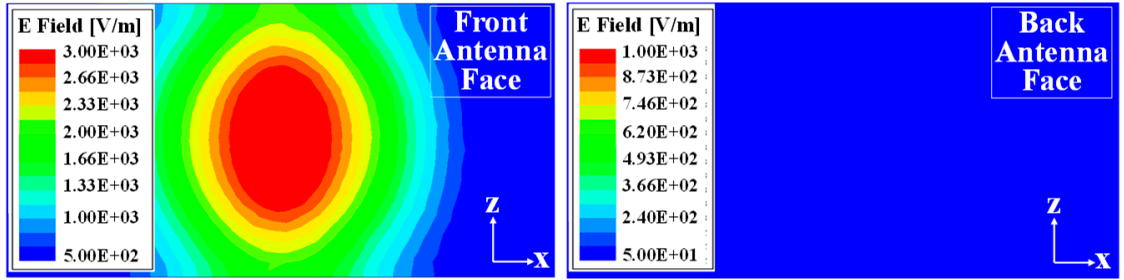

(c)

Figure 4. The electric field in the $\mathrm{x}-\mathrm{z}$ plane at the front and back faces of the dipole antenna. (a) With the optimal $\lambda_{d} \times \lambda_{d}$ rectangular fence. (b) With the $1.2 \lambda_{d} \times \lambda_{d}$ rectangular fence. (c) With the $115^{\circ}$ tapered $\mathrm{V}$-fence.

If an intermediate point between the $\lambda_{d} \times \lambda_{d}$ rectangular fence and the $115^{\circ}$ tapered $\mathrm{V}$-fence dipole is required, a $105^{\circ}$ tapered $\mathrm{V}$-fence can be chosen, which achieved $8.1 \mathrm{dBi}$ gain, $120.5^{\circ} \mathrm{HPBW}_{\mathrm{El}}$, and $30.4 \mathrm{~dB}$ F/B. However, a better fence can be designed for that case to provide enhanced F/B. Hence, a third fence shape with moderate tapering was investigated, namely, the U-shaped fence, which has a curved tapering, as shown in Figure 1c. The U-fence is defined by its size span $X_{F E N C E} \times Y_{\text {FENCE }}$ (set to $\lambda_{d} \times \lambda_{d}$ ) and the curve radius $(R)$. By setting $R$ to $3.2 \mathrm{~mm}$ for optimal performance, the U-fence dipole attained $37.2 \mathrm{~dB}$ F/B. 


\subsection{Performance Comparison of the Different Fence Shapes}

In this section, the performance of the dipole with the different fence shapes is compared and discussed. For fair comparison, all the fences spanned the same size of $X_{\mathrm{FENCE}} \times \mathrm{Y}_{\mathrm{FENCE}}=\lambda_{\mathrm{d}} \times \lambda_{\mathrm{d}}$. The simulated zoomed-in radiation patterns in the elevation plane for the $\lambda_{d} \times \lambda_{d}$ rectangular fence, U-fence, and $115^{\circ}$ tapered V-fence dipoles-denoted by $\mathrm{R} 1 \times 1, \mathrm{U} 1 \times 1$, and $\mathrm{V} 1 \times 1$, respectively—are illustrated in Figure 5a. With increased fence tapering, as we went from the rectangular fence to the U-fence to the $\mathrm{V}$-fence, the gain increased, while the $\mathrm{HPBW}_{\mathrm{El}}$ decreased with approximately no effect on the $\mathrm{F} / \mathrm{B}$, and in all cases a wide $\mathrm{HPBW}_{\mathrm{El}}$ greater than $108^{\circ}$ was achieved. Hence, the proposed electric dipole provides an additional design degree of freedom for $5 \mathrm{G}$ handset device antennas, where the radiation pattern and gain can be controlled by amount of fence tapering. Another important advantage of the proposed structure is its stable radiation pattern over a wide bandwidth, ranging from $22.5 \mathrm{GHz}$ to $34 \mathrm{GHz}$, which makes it capable of supporting multiple $5 \mathrm{G}$ frequency bands. Figure $5 \mathrm{~b}$ provides the simulated/measured radiation performance of the dipole with its different fence shapes versus frequency. As can be noted, in addition to the high gain, HPBW, and F/B, the proposed vertically-polarized structure provides low cross-polarization (X-pol) levels.

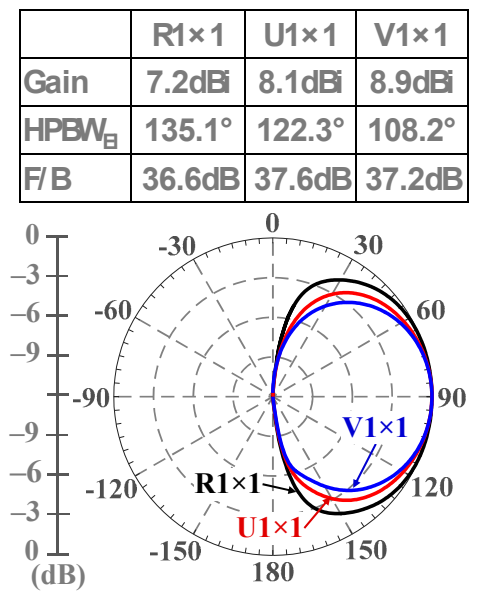

(a)

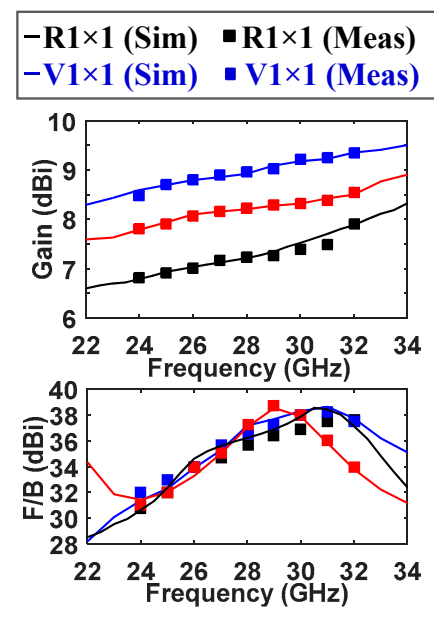

(b)

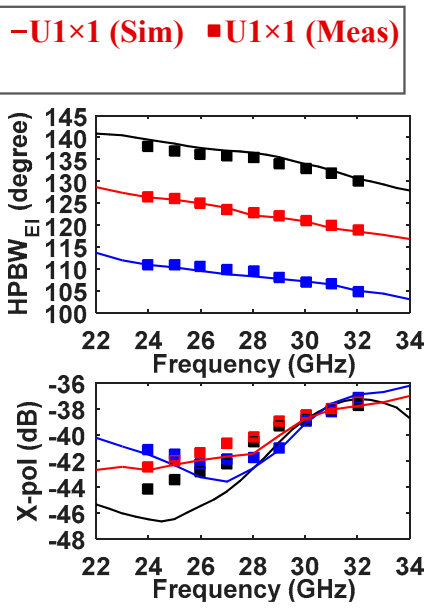

Figure 5. (a) The simulated radiation pattern in the elevation plane for the dipole with rectangular $(\mathrm{R} 1 \times 1), \mathrm{U}-(\mathrm{U} 1 \times 1)$, and V-fence $(\mathrm{V} 1 \times 1)$ at $28 \mathrm{GHz}$. $(\mathbf{b})$ The simulated and measured radiation performance of the electric dipole with the different fence shapes versus frequency.

The dipole feed is composed of a parallel strip line (PS), a substrate-integrated waveguide (SIW), and a SIW-to-PS transition. The bandwidth can be controlled by adjusting the dimensions of the SIW-to-PS transition. The $7 \mathrm{~mm}$ width SIW employs $0.6 \mathrm{~mm}$ diameter vias with $0.8 \mathrm{~mm}$ pitch. The SIW-to-PS transition is designed by gradually tapering the SIW width with a $59^{\circ}$ tapering angle, using 4 vias with slightly higher pitch of $0.88 \mathrm{~mm}$. It is also instructive to study the mutual coupling between the adjacent dipole array elements for the different fence shapes. Figure 6 provides the S12 plot of the two adjacent elements of the 4 port-a 4 element electric dipole array with different fence shapes, showing that the mutual coupling between the closest two dipole elements was less than $-21 \mathrm{~dB}$ for the $\lambda_{d} \times \lambda_{d}$ rectangular fence, the U-fence, and the $115^{\circ}$ tapered $V$-fence cases, indicating minimal interaction between the different dipole elements. However, the S12 degraded for the case of the $1.2 \lambda_{d} \times \lambda_{d}$ rectangular fence. This is another reason why it is better to use fence shaping over resizing the rectangular fence when a higher gain is required. 


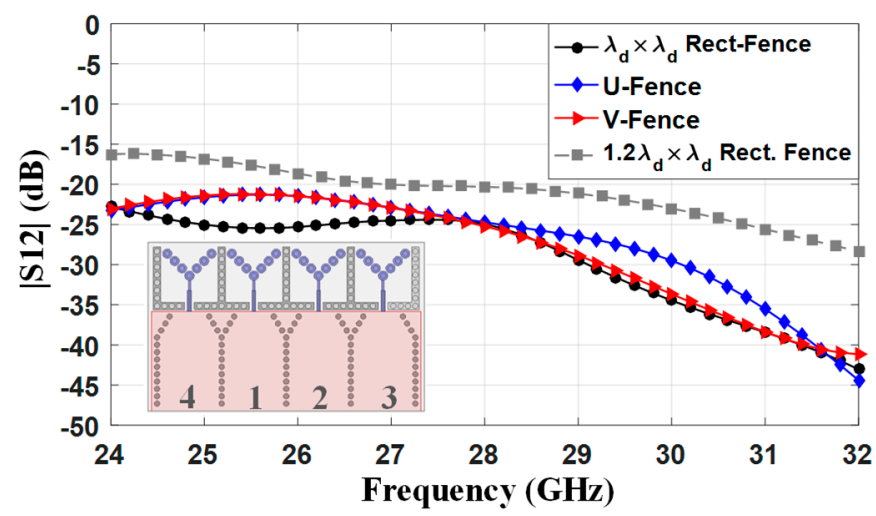

Figure 6. The simulated $|\mathrm{S} 12|$ of the adjacent dipole array elements for the different fence shapes.

\section{The Measurement and Simulated Results}

The fabricated prototypes are shown in Figure 7, where a single element, $2 \times 1$, and $4 \times 1$ arrays were fabricated for each of the $\lambda_{d} \times \lambda_{d}$ rectangular fence, the U-fence, and the $115^{\circ} \mathrm{V}$-fence dipoles. For the sake of testing the arrays, an SIW divider was employed. Practically, the SIW divider will not be needed where every antenna element is directly connected on the PCB to a pin of the RF phase shifter required to provide the appropriate phase shifting for beam steering. The measured/simulated radiation patterns of the fabricated prototypes are shown in Figure 8 at $28 \mathrm{GHz}$, where the $4 \times 1$ array achieved a measured gain/HPBW $\mathrm{El}_{\mathrm{El}} / \mathrm{side}$-lobe level (SLL) of $12.6 \mathrm{dBi} / 133.1^{\circ} / 10.6 \mathrm{~dB}, 13.5 \mathrm{dBi} / 118^{\circ} / 14.6 \mathrm{~dB}$ and $14.2 \mathrm{dBi} / 104^{\circ} / 13.1 \mathrm{~dB}$ for the rectangular-, $\mathrm{U}-$, and $\mathrm{V}$-fences, respectively. The $\mathrm{S} 11$ parameters of the dipole with rectangular, $U$-, and V-shaped fences in Figure 9 show a simulated/measured bandwidth of $6.94 / 7.23 \mathrm{GHz}, 6.6 / 6.5 \mathrm{GHz}$, and $6.4 / 6.42 \mathrm{GHz}$, respectively. Figure 10 shows the simulated and measured gain/directivity of the fabricated prototypes over the operating bandwidth. Table 2 provides a comparison of the proposed dipole array, with state-of-the-art mmWave linearly polarized mobile device antenna arrays showing superior performance from the proposed dipole.
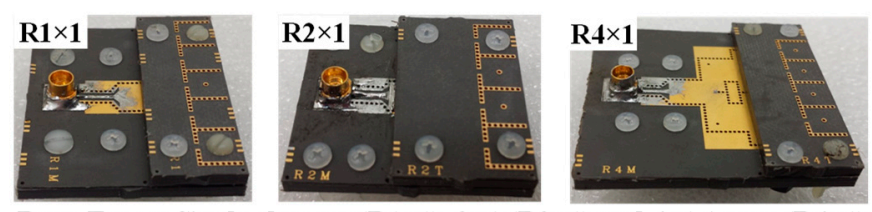

Rect. Fence: Single element $(\mathrm{R} 1 \times 1), 2 \times 1(\mathrm{R} 2 \times 1)$ and $4 \times 1$ Array $(\mathrm{R} 4 \times 1)$
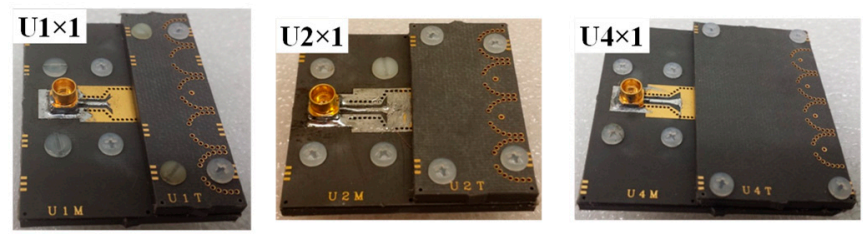

U-Fence: Single element $(\mathrm{U} 1 \times 1), 2 \times 1(\mathrm{U} 2 \times 1)$ and $4 \times 1$ Array $(\mathrm{U} 4 \times 1)$
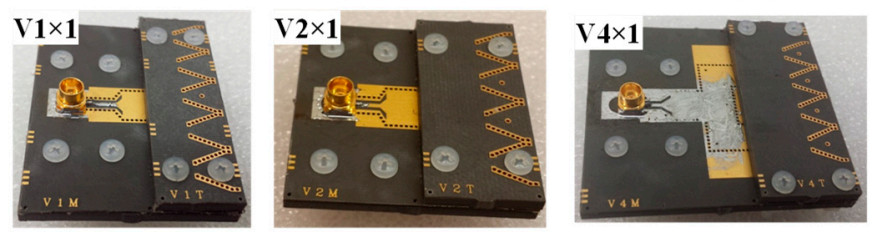

V-Fence: Single element (V1×1), $2 \times 1(\mathrm{~V} 2 \times 1)$ and $4 \times 1$ Array $(\mathrm{V} \times 1)$

Figure 7. The fabricated antennas prototypes. 


\begin{tabular}{|c|c|c|c|}
\hline --- Co-pol Elev. (Sim) & — Co-pol Elev. (Meas) & --- Co-pol Az. (Sim) & — Co-pol Az. (Meas) \\
\hline --- X-pol Elev. (Sim) & - X-pol Elev. (Meas) & --- X-pol Az. (Sim) & -X-pol Az. (Meas) \\
\hline
\end{tabular}
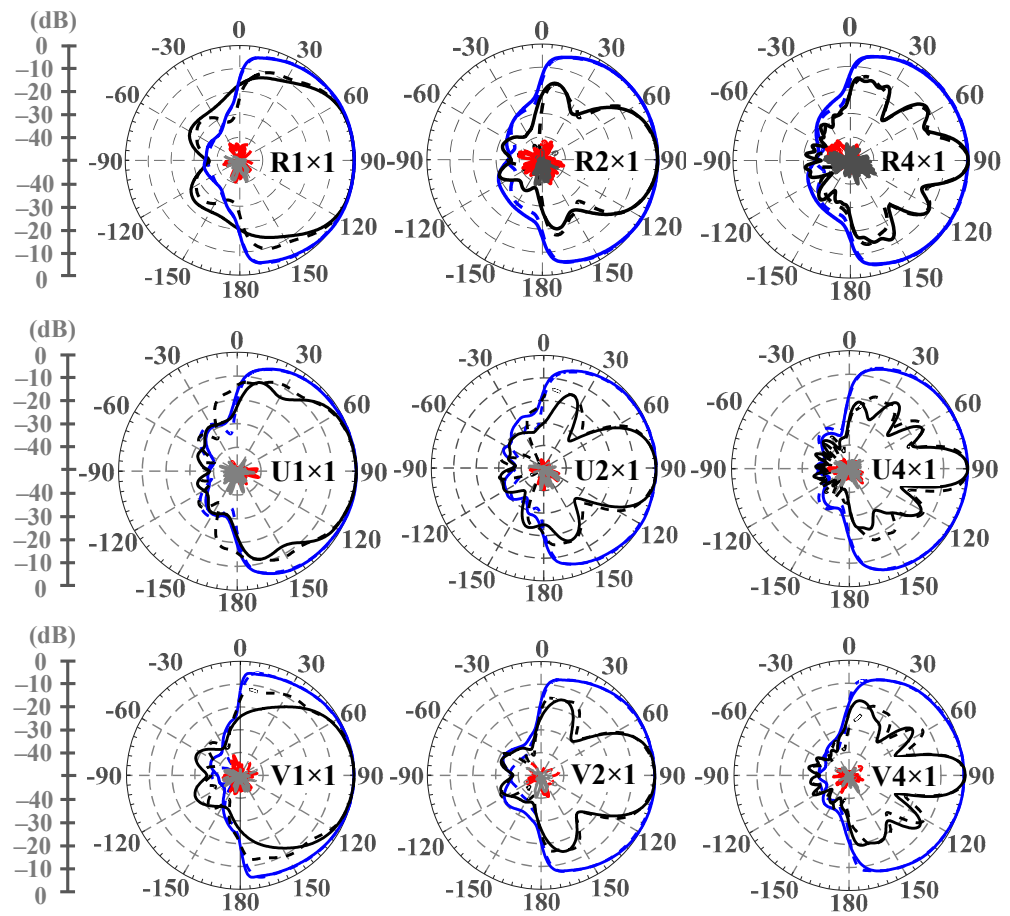

Figure 8. The simulated/measured radiation patterns at $28 \mathrm{GHz}$.

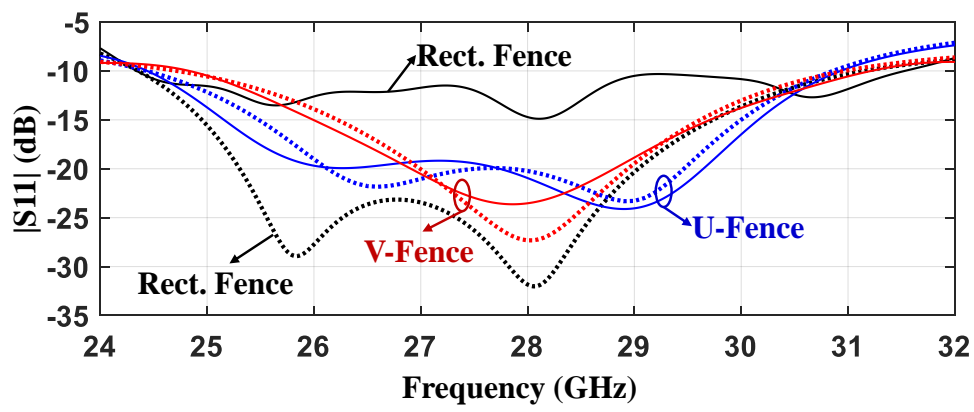

Figure 9. The measured (solid line) and simulated (dotted line) S11 plots for the single element dipoles.

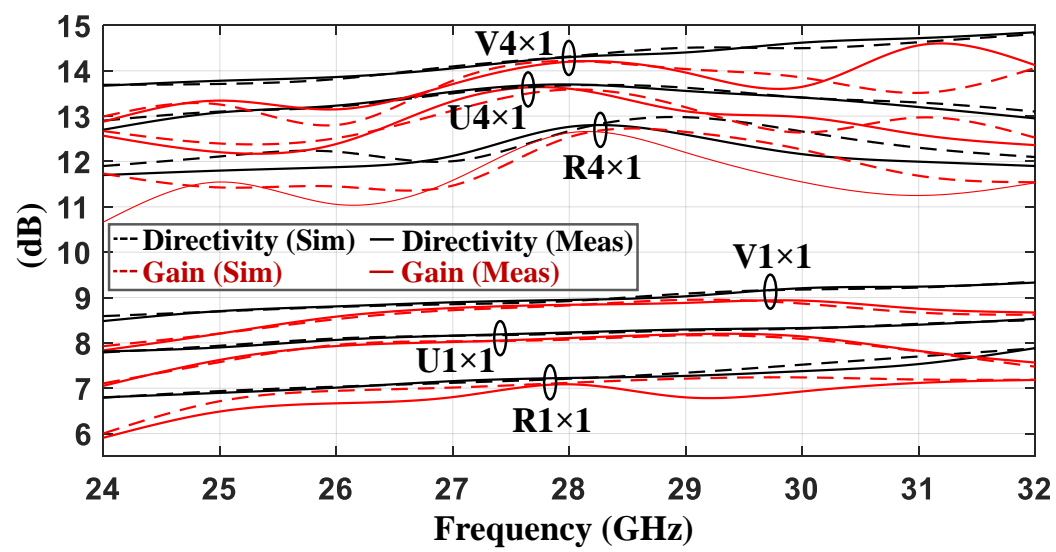

Figure 10. The simulated/measured gain/directivity versus frequency for the fabricated prototypes. 
Table 2. Comparison with state-of-the-art $28 \mathrm{GHz}$ linearly polarized mobile device antennas.

\begin{tabular}{cccccccc}
\hline & Structure & $\begin{array}{c}\text { BW } \\
(\mathbf{G H z})\end{array}$ & $\begin{array}{c}\text { Gain } \\
(\mathbf{d B i})\end{array}$ & $\mathbf{H P B W}_{\mathrm{El}}$ & $\begin{array}{c}\mathrm{F} / \mathbf{B} \\
(\mathbf{d B})\end{array}$ & $\begin{array}{c}\text { X-pol } \\
\mathbf{( d B})\end{array}$ & Size \\
\hline$[12]$ & $\begin{array}{c}16 \times 1 \text { mesh grid } \\
\text { array }\end{array}$ & 3 & 10.9 & $109^{\circ}$ & 15 & $\mathrm{~N} / \mathrm{A}$ & $8.32 \lambda_{\mathrm{d}} \times 1.06 \lambda_{\mathrm{d}} \times 0.2 \lambda_{\mathrm{d}}$ \\
\hline$[14]$ & 11 dipoles + Horn & 11 & $9-12$ & $60^{\circ}$ & $10-20$ & $<-25$ & $4.5 \lambda_{\mathrm{d}} \times 6.57 \lambda_{\mathrm{d}} \times 0.86 \lambda_{\mathrm{d}}$ \\
\hline$[15]$ & $16 \times 1$ slot array & 2.5 & 15 & $70^{\circ}$ & 10 & $\mathrm{~N} / \mathrm{A}$ & $7.1 \lambda_{\mathrm{d}} \times 0.21 \lambda_{\mathrm{d}} \times 0.55 \lambda_{\mathrm{d}}$ \\
\hline \multirow{2}{*}{$\begin{array}{c}\text { This } \\
\text { Work }\end{array}$} & Rect-fence [16] & 7.23 & 12.61 & $133.1^{\circ}$ & 36.6 & $<-39.8$ & $3.84 \lambda_{\mathrm{d}} \times 0.94 \lambda_{\mathrm{d}} \times 0.67 \lambda_{\mathrm{d}}$ \\
\cline { 2 - 7 } & U-fence & 6.5 & 13.5 & $118^{\circ}$ & 36.1 & $<-41.1$ & $4.36 \lambda_{\mathrm{d}} \times 0.95 \lambda_{\mathrm{d}} \times 0.67 \lambda_{\mathrm{d}}$ \\
\hline & V-fence & 6.42 & 14.2 & $104^{\circ}$ & 36.2 & $<-41.3$ & $4.33 \lambda_{\mathrm{d}} \times 0.97 \lambda_{\mathrm{d}} \times 0.67 \lambda_{\mathrm{d}}$ \\
\hline
\end{tabular}

\section{Conclusions}

In this work, fence shaping for substrate-integrated electric dipole antennae was presented. The concept of fence shaping and tapering was discussed with the aid of V-shaped fence and U-shaped fence dipole antennas, for which the performances were compared with the conventional rectangular fence dipole antenna. By fence shaping, as an additional degree of freedom in the design, one can modulate the radiation performance of the antenna while achieving a gain and $\mathrm{HPBW}_{\mathrm{El}}$ of at least $12.6 \mathrm{dBi}$ and $104^{\circ}$ from a $4 \times 1$ array, respectively. Overall, the proposed structure achieved excellent and stable radiation performance over a wide frequency bandwidth, making it suitable for multiple high-band 5G applications.

Author Contributions: The authors contributions towards this research article is as follows; conceptualization, W.E.-H., R.M. and P.M.; methodology, W.E.-H., R.M. and P.M.; validation, W.E.-H.; formal analysis, W.E.-H.; investigation, W.E.-H., R.M. and P.M.; resources, J.M and P.M. writing-original draft preparation, W.E.-H.; writing-review and editing, W.E.-H., R.M. and P.M..; supervision, R.M, M.H and P.M.; project administration, P.M.

Funding: This research was funded by TELUS Communications.

Conflicts of Interest: The authors declare no conflict of interest.

\section{References}

1. Rahman, M.; NagshvarianJahromi, M.; Mirjavadi, S.S.; Hamouda, A.M. Compact UWB Band-Notched Antenna with Integrated Bluetooth for Personal Wireless Communication and UWB Applications. Electronics 2019, 8, 158. [CrossRef]

2. Ameen, H.A.; Abdelmonem, K.; Elgamal, M.A.; Mousa, M.A.; Hamada, O.; Zakaria, Y.; Abdalla, M.A. A $28 \mathrm{GHz}$ Four-Channel Phased-Array Transceiver in 65-nm CMOS Technology for 5G Applications. Int. J. Electron. Commun. 2019, 98, 19-28. [CrossRef]

3. Hong, W.; Jiang, Z.H.; Yu, C.; Zhou, J.; Chen, P.; Yu, Z.; Zhang, H.; Yang, B.; Pang, X.; Jiang, M.; et al. Multibeam Antenna Technologies for 5G Wireless Communications. IEEE Trans. Antennas Propag. 2017, 65, 6231-6249. [CrossRef]

4. CISCO Systems. Cisco Visual Networking Index: Global Mobile Data Traffic Forecast Update, 2016-2021 White Paper, February 2017. Available online: http://www.cisco.com/c/en/us/solutions/collateral/serviceprovider/visual-networking-index-vni/mobile-white-paper-c11-520862.html (accessed on 17 April 2019).

5. Hong, T.; Zhao, Z.; Jiang, W.; Xia, S.; Liu, Y.; Gong, S. Dual-Band SIW Cavity-Backed Slot Array Using TM020 and TM120 Modes for 5G Applications. IEEE Trans. Antennas Propag. 2019, 67, 3490-3495. [CrossRef]

6. Roh, W.; Seol, J.Y.; Park, J.; Lee, B.; Lee, J.; Kim, Y.; Cho, J.; Cheun, K.; Aryanfar, F. Millimeter-wave beamforming as an enabling technology for $5 \mathrm{G}$ cellular communications: Theoretical feasibility and prototype results. IEEE Commun. Mag. 2014, 52, 106-113. [CrossRef]

7. Rahman, M.; NaghshvarianJahromi, M.; Mirjavadi, S.S.; Hamouda, A.M. Bandwidth Enhancement and Frequency Scanning Array Antenna Using Novel UWB Filter Integration Technique for OFDM UWB Radar Applications in Wireless Vital Signs Monitoring. Sensors 2018, 18, 3155. [CrossRef] [PubMed]

8. Hong, W.; Baek, K.H.; Lee, Y.; Kim, Y.; Ko, S.T. Study and prototyping of practically large-scale mmWave antenna systems for 5G cellular devices. IEEE Commun. Mag. 2014, 52, 63-69. [CrossRef] 
9. Monavar, F.M.; Shamsinejad, S.; Mirzavand, R.; Melzer, J.; Mousavi, P. Beam-Steering SIW Leaky-Wave Subarray with Flat-Topped Footprint for 5G Applications. IEEE Trans. Antennas Propag. 2017, 65, 1108-1120. [CrossRef]

10. Honari, M.M.; Mirzavand, R.; Melzer, J.; Mousavi, P. A New Aperture Antenna Using Substrate Integrated Waveguide Corrugated Structures for 5G Applications. IEEE Antennas Wirel. Propag. Lett. 2017, 16, $254-257$. [CrossRef]

11. Hong, W.; Baek, K.H.; Ko, S. Millimeter-Wave 5G Antennas for Smartphones: Overview and Experimental Demonstration. IEEE Trans. Antennas Propag. 2017, 65, 6250-6261. [CrossRef]

12. Hong, W.; Baek, K.; Lee, Y.; Kim, Y.G. Design and analysis of a low-profile $28 \mathrm{GHz}$ beam steering antenna solution for Future 5G cellular applications. In Proceedings of the 2014 IEEE MTT-S International Microwave Symposium (IMS2014), Tampa, FL, USA, 1-6 June 2014; pp. 1-4.

13. Hong, W.; Ko, S.; Lee, Y.; Baek, K.H. Compact $28 \mathrm{GHz}$ antenna array with full polarization flexibility under yaw, pitch, roll motions. In Proceedings of the 2015 9th European Conference on Antennas and Propagation (EuCAP), Lisbon, Portugal, 13-17 April 2015; pp. 1-3.

14. Wang, J.; Li, Y.; Ge, L.; Wang, J.; Chen, M.; Zhang, Z.; Li, Z. Wideband Dipole Array Loaded Substrate Integrated H-Plane Horn Antenna for Millimeter Waves. IEEE Trans. Antennas Propag. 2017, 65, 5211-5219. [CrossRef]

15. Yu, B.; Yang, K.; Sim, C.Y.D.; Yang, G. A Novel 28 GHz Beam Steering Array for 5G Mobile Device with Metallic Casing Application. IEEE Trans. Antennas Propag. 2018, 66, 462-466. [CrossRef]

16. El-Halwagy, W.; Mirzavand, R.; Melzer, J.; Hossain, M.; Mousavi, P. Investigation of Wideband Substrate-Integrated Vertically-Polarized Electric Dipole Antenna and Arrays for mm-Wave 5G Mobile Devices. IEEE Access 2018, 6, 2145-2157. [CrossRef]

17. Li, Y.; Luk, K.M. A Multibeam End-Fire Magnetoelectric Dipole Antenna Array for Millimeter-Wave Applications. IEEE Trans. Antennas Propag. 2016, 64, 2894-2904. [CrossRef]

18. Wang, J.; Li, Y.; Ge, L.; Wang, J.; Luk, K.M. A 60 GHz Horizontally Polarized Magnetoelectric Dipole Antenna Array with 2-D Multibeam Endfire Radiation. IEEE Trans. Antennas Propag. 2017, 65, 5837-5845. [CrossRef]

19. FCC. Fact Sheet: Spectrum Frontiers Order to Identify, Open Up Vast Amounts of New High-Band Spectrum for Next Generation (5G) Wireless Broadband (As Adopted). Available online: https://apps.fcc.gov/edocs_ public/attachmatch/DOC-340310A1.pdf (accessed on 15 July 2016).

20. OFCOM. 5G Spectrum Access at $26 \mathrm{GHz}$ and Update on Bands Above $30 \mathrm{GHz}$. Available online: https: //www.ofcom.org.uk/_data/assets/pdf_file/0014/104702/5G-spectrum-access-at-26-GHz.pdf (accessed on 28 July 2017).

21. Rikuta, Y.; Arai, H.; Ebine, Y. Reflector shape optimization for FB ratio of dipole antenna. In Proceedings of the APMC 2001 Asia-Pacific Microwave Conference (Cat. No.01TH8577), Taipei, Taiwan, 3-6 December 2001; Volume 3, pp. 1068-1071.

22. Feng, B.; Li, S.; An, W.; Yin, S.; Li, J.; Qiu, T. U-shaped bow-tie magneto-electric dipole antenna with a modified horned reflector for ultra-wideband applications. IET Microw. Antennas Propag. 2014, 8, 990-998. [CrossRef]

23. El-Halwagy, W.; Mirzavand, R.; Melzer, J.; Hossain, M.; Mousavi, P. A Substrate-Integrated Fan-Beam Dipole Antenna with Varied Fence Shape for mm-Wave 5G Wireless. In Proceedings of the 2018 IEEE International Symposium on Antennas and Propagation\&USNC/URSI National Radio Science Meeting, Boston, MA, USA, 8-13 July 2018; pp. 251-252.

(C) 2019 by the authors. Licensee MDPI, Basel, Switzerland. This article is an open access article distributed under the terms and conditions of the Creative Commons Attribution (CC BY) license (http://creativecommons.org/licenses/by/4.0/). 